\title{
Study on Comprehensive Evaluation of Smart Growth Cities \\ Cheng Wang
}

\author{
School of Mathematics and Economics, Hubei University of Education, \\ Wuhan 430205, P. R. China \\ wangc80@163.com
}

\begin{abstract}
Keywords: Smart growth cities; Fuzzy comprehensive evaluation; Sustainable development.
\end{abstract}
\begin{abstract}
This paper studied the problem of comprehensive evaluation of smart growth cities from three dimensions of sustainable development. Concretely, an evaluation system for smart growth cities from the dimensions of sustainable development - economic, environmental and social, is constructed, then a fuzzy comprehensive evaluation method is presented to evaluate the development level of smart growth cities, and an application example is given to highlight the implementation, availability, and feasibility of the proposed comprehensive evaluation method.
\end{abstract}

\section{Introduction}

Many communities are implementing smart growth initiatives in an effort to consider long range, sustainable planning goals. "Smart growth is about helping every town and city become a more economically prosperous, socially equitable, and environmentally sustainable place to live. Smart growth focuses on building cities that embrace the E's of sustainability-Economically prosperous, socially Equitable, and Environmentally Sustainable. This task is more important than ever because the world is rapidly urbanizing. It is projected that by 2050, 66 percent of the world's population will be urban - this will result in a projected 2.5 billion people being added to the urban population. Consequently, urban planning has become increasingly important and necessary to ensure that people have access to equitable and sustainable homes, resources and jobs.

Smart growth is an urban planning theory that originated in 1990's, after decades of practice, people summarize 10 basic principles for smart growth that deeply rooted in the 3E's of sustainability - Economically prosperous, socially Equitable, and Environmentally Sustainable [1]. The continuing urbanization and overall growth of the world's population is projected to add 2.5 billion people to the urban population by 2050, meanwhile about 66 percent of the world's population will be living in cities [2]. These circumstances call for cities to function smarter to provide dignity for the increasing urban dwellers.

\section{The Evaluation Index System}

In this section, an evaluation system for evaluate the development level of smart growth cities was established. Drawing from the existing related research [3-8], we take into account three dimensions of sustainable development - economic, environmental and social to construct an evaluation system as shown in Table 1.

Each attribute in Table 1 is briefly described as follows.

$A_{1}$ GDP growth rate, which reflects a country or region's economy vitality. In general, the GDP growth rate of developing countries are greater than developed countries.

$A_{2}$ GDP per capita, is a more persuasive criteria than the region's total GDP. A metropolis with huge GDP volume does not necessarily belong to the smart cities club.

$A_{3}$ Service industry proportion. Smart cities generally have robust service industry, thus they can focus on preserving open space, farmland, natural beauty, and critical environmental areas.

$A_{4}$ Imports-Exports. A city that keeps a close relation with the outer economy tends to work smarter.

$A_{5} \mathrm{AQI}$, which is based on the five "criteria" pollutants: ground-level ozone, particulate matter, carbon monoxide, sulfur dioxide, and nitrogen dioxide. 
$A_{6}$ Forest coverage, which reflects how "green" a city is, including natural parks, community gardens and historical sites area.

$A_{7} \mathrm{PM} 2.5$. Considering that the AQI index may be too general, we also choose PM2.5 index to reflect the air quality.

$A_{8}$ Crimes rate, which reflects the social security level.

$A_{9}$ Health care rate. Extensive public health care can give citizens sense of security, fairness and dignity.

$A_{10}$ Unemployment rate. Low unemployment rate contribute to public anxiety reduction and public intelligence emergence.

Table 1. Evaluation index system for evaluate the development level of smart growth cities

\begin{tabular}{ll}
\hline First level attribute & Second level attribute \\
\hline \multirow{4}{*}{ Economic criterion } & $A_{1}$ GDP growth rate \\
& $A_{2}$ GDP per capita \\
& $A_{3}$ Service industry proportion \\
& $A_{4}$ Imports-Exports \\
\hline \multirow{3}{*}{ Environmental criterion } & $A_{5}$ AQI \\
& $A_{6}$ Forest coverage \\
& $A_{7}$ PM2.5 \\
\hline \multirow{3}{*}{ Social criterion } & $A_{8}$ Crimes rate \\
& $A_{9}$ Health care rate \\
& $A_{10}$ Unemployment rate \\
\hline
\end{tabular}

\section{Fuzzy Comprehensive Evaluation Method}

Fuzzy set theory [9-17] has been developed and extensively applied since 1965 (Zadeh, 1965). It was designed to supplement the interpretation of linguistic or measured uncertainties for real-world random phenomena. We use the data of Zhuhai City to show the whole process.

Step1: Establish the factor set.

We have already articulate our metrics for ranking. Totally, there are 10 second level attributes are given to They constitute the factor set $\mathrm{U}$ :

$U=\left[A_{1}, A_{2}, \ldots, A_{10}\right]$

Step2: Establish the evaluation set.

We divide cities' performance in every norms into five levels, which denoted as $10,8,6,4,2$, and then rate the four levels for the convenience of quantitative analysis. We denote the evaluation set $V$ as:

$V=[10,8,6,4,2]$

Step 3: Determine the degree matrix of membership.

We use Delphi method to determine the membership degree matrix. Delphi method, namely Expert Investigation Method, is a structured communication technique or method, originally developed as a systematic, interactive forecasting method which relies on a panel of experts.

The experts answer questionnaires in two or more rounds. The number of experts is $n$. We denote the membership degree of the factor $u_{i j}$ as $r_{i j}$, in which $i$ denotes the $i$ th element in factor set, and $j$ denotes the $j$ th element in evaluation set.

From Table 1, we can get the degree matrix of membership as follows.

$$
R_{1}=\left(\begin{array}{lllll}
0.07 & 0.13 & 0.22 & 0.35 & 0.23 \\
0.16 & 0.39 & 0.34 & 0.08 & 0.03 \\
0.18 & 0.29 & 0.32 & 0.15 & 0.06 \\
0.12 & 0.28 & 0.34 & 0.21 & 0.05
\end{array}\right)
$$




$$
\begin{aligned}
& R_{2}=\left(\begin{array}{lllll}
0.24 & 0.38 & 0.26 & 0.08 & 0.04 \\
0.12 & 0.24 & 0.3 & 0.26 & 0.08 \\
0.32 & 0.33 & 0.18 & 0.11 & 0.06
\end{array}\right), \\
& R_{3}=\left(\begin{array}{lllll}
0.17 & 0.29 & 0.32 & 0.18 & 0.04 \\
0.07 & 0.10 & 0.46 & 0.22 & 0.15 \\
0.29 & 0.42 & 0.19 & 0.07 & 0.03
\end{array}\right) .
\end{aligned}
$$

Table 2. The evaluation results given by experts

\begin{tabular}{c|l|ccccc}
\hline $\begin{array}{c}\text { First level } \\
\text { attribute }\end{array}$ & \multicolumn{1}{|c|}{ Second level attribute } & \multicolumn{5}{|c}{$r_{i j}$} \\
\hline \multirow{3}{*}{$\begin{array}{c}\text { Economic } \\
\text { criterion }\end{array}$} & $A_{1}$ GDP growth rate & 0.07 & 0.13 & 0.22 & 0.35 & 0.23 \\
& $A_{2}$ GDP per capita & 0.16 & 0.39 & 0.34 & 0.08 & 0.03 \\
& $A_{3}$ Service industry proportion & 0.18 & 0.29 & 0.32 & 0.15 & 0.06 \\
& $A_{4}$ Imports-Exports & 0.12 & 0.28 & 0.34 & 0.21 & 0.05 \\
\hline \multirow{2}{*}{$\begin{array}{c}\text { Environmental } \\
\text { criterion }\end{array}$} & $A_{5}$ AQI & 0.24 & 0.38 & 0.26 & 0.08 & 0.04 \\
& $A_{6}$ Forest coverage & 0.12 & 0.24 & 0.3 & 0.26 & 0.08 \\
& $A_{7}$ PM2.5 & 0.32 & 0.33 & 0.18 & 0.11 & 0.06 \\
\hline \multirow{3}{*}{ Social criterion } & $A_{8}$ Crimes rate & 0.17 & 0.29 & 0.32 & 0.18 & 0.04 \\
& $A_{9}$ Health care rate & 0.07 & 0.1 & 0.46 & 0.22 & 0.15 \\
& $A_{10}$ Unemployment rate & 0.29 & 0.42 & 0.19 & 0.07 & 0.03 \\
\hline
\end{tabular}

Step 4: Determine the weights matrix.

Applying Delphi method to the process, we obtain the following results.

First-layer norms weight: $P=(0.4,0.3,0.3)$.

Second-layer norms weight:

$P_{1}=(0.2,0.3,0.3,0.2), \quad P_{2}=(0.4,0.4,0.2), \quad P_{3}=(0.3,0.3,0.4)$.

Step 5: Results and analysis. We define the measure of fuzzy evaluation as $B$.

First-level fuzzy evaluation:

$B 1=P_{1} \cdot R_{1}=[0.140,0.286,0.310,0.181,0.083]$,

$B_{2}=P_{2} \cdot R_{2}=[0.208,0.314,0.260,0.158,0.060]$,

$B 3=P_{3} \cdot R 3=[0.188,0.285,0.310,0.148,0.069]$.

Second-level fuzzy evaluation:

$B=A \cdot R=[0.1748,0.2941,0.2950,0.1642,0.0719,0.0719]$.

Thus, the final score of Zhuhai City is $S=B \dot{V}^{T}=6.6714$.

\section{Conclusions}

In this paper, the problem of comprehensive evaluation of smart growth cities from three dimensions of sustainable development is studied. First, an evaluation system for smart growth cities from the dimensions of sustainable development - economic, environmental and social, is constructed, then a fuzzy comprehensive evaluation method is presented to evaluate the development level of smart growth cities, and the data of Zhuhai City is used to show the whole process of this fuzzy comprehensive evaluation method, and we obtain a satisfied results.

\section{Acknowledgments}

This work is supported by the Natural Science Foundation of Hubei Province (No. 2015CFB420). 


\section{References}

[1] C.J. Rao, M. Goh, J.J. Zheng, Decision Mechanism for Supplier Selection under Sustainability. International Journal of Information Technology and Decision Making 16(1) (2017) 87-115.

[2] C.J. Rao, P. Li, Multi-stage sequential uniform price auction mechanism for divisible goods, Expert Systems with Applications 40(15) (2013) 6105-6114.

[3] C.T. Chen, C.T. Lin, S.F. Huang, A fuzzy approach for supplier evaluation and selection in supply chain management, International Journal of Production Economics 102 (2006) 289-301.

[4] C.J. Rao, Location selection of sustainability city logistics centers, Transportation Research Part D: Transport and Environment 36 (2015) 29-44.

[5] C.J. Rao, X.P. Xiao, M. Goh, J.J. Zheng, J.H. Wen, Compound mechanism design of supplier selection based on multi-attribute auction and risk management of supply chain, Computers and Industrial Engineering 105 (2017) 63-75.

[6] M. Seuring, S. Muller, From a literature review to a conceptual framework for sustainable supply chain management, Journal of Cleaner Production 16 (2017) 1699-1710.

[7] P. Rao, D. Holt, Do green supply chains lead to competitiveness and economic performance? International Journal of Operations and Production Management 25 (2005) 898-916.

[8] C.J. Rao, J. Peng, Fuzzy group decision making model based on credibility theory and gray relative degree, International Journal of Information Technology and Decision Making 8 (2009) 515-527.

[9] C.J. Rao, X.P. Xiao, J. Peng, Novel combinatorial algorithm for the problems of fuzzy grey multi-attribute group decision making, Journal of Systems Engineering and Electronics 18(4) (2007) 774-780.

[10] S.H. Ma, Y. Lin, Z.Q. Chen, Supply Chain Management (translated from Chinese), China Machine Press, Beijing, 2000.

[11]C.J. Rao, Y. Zhao, S.H. Ma, Procurement decision making mechanism of divisible goods based on multi-attribute auction, Electronic Commerce Research and Applications 11(4) (2012) 397-406.

[12]C.J. Rao, Y. Zhao, J.J. Zheng, C. Wang, Z.W. Chen, An extended uniform price auction mechanism of homogeneous divisible goods: supply optimization and non-strategic bidding, International Journal of Production Research 54(13) (2016) 4028-4042.

[13]J.D. Qin, X.W. Liu, Witold Pedryczc, An extended TODIM multi-criteria group decision making method for green supplier selection in interval type-2 fuzzy environment, European Journal of Operational Research 258 (2017) 626-638.

[14] C.J. Rao, Y. Zhao, Z.C. Zhang, Multi-attribute auction method based on grey relational degree of hybrid sequences, The Journal of Grey System 21(2) (2009) 175-184.

[15]C.J. Rao, J.J. Zheng, Z. Hu, M. Goh, Compound mechanism design on multi-attribute and multi-source procurement of electricity coal, Scientia Iranica, Transactions E: Industrial Engineering 23(3) (2016) 1384-1398.

[16]J.J.H. Liou, Y.C. Chuang, G.H. Tzeng, A fuzzy integral-based model for supplier evaluation and improvement, Information Sciences 266 (2014) 199-217.

[17]C.J. Rao, J.J. Zheng, C. Wang, X.P. Xiao, A hybrid multi-attribute group decision making method based on grey linguistic 2-tuple, Iranian Journal of Fuzzy Systems 13(2) (2016) 37-59. 